\title{
Serum sodium concentration and the progression of established chronic kidney disease
}

\author{
Nicholas I. Cole ${ }^{1} \mathbb{D} \cdot$ Rebecca J. Suckling $^{1} \cdot$ Vipula Desilva ${ }^{1} \cdot$ Feng J. He ${ }^{2} \cdot$ Graham A. MacGregor $^{2} \cdot$ Pauline A. Swift $^{1}$
}

Received: 8 July 2018 / Accepted: 29 September 2018 / Published online: 16 October 2018

(c) The Author(s) 2018

\begin{abstract}
Background Higher serum sodium concentration has been reported to be a risk factor for the development of incident chronic kidney disease (CKD), but its relationship with the progression of established CKD has not been investigated. We hypothesised that increased serum sodium concentration is a risk factor for estimated glomerular filtration rate (eGFR) decline in CKD.

Methods This was a retrospective cohort study using data collected over a 6-year period, with baseline data obtained during the first 2 years. We included patients known to our renal service who had had a minimum of three blood tests every 2 years and an eGFR of $<60 \mathrm{~mL} / \mathrm{min} / 1.73 \mathrm{~m}^{2}$ at baseline. Exclusion criteria were renal replacement therapy, diabetes mellitus, heart failure and decompensated liver disease. A multiple linear regression model investigated the relationship between baseline serum sodium and eGFR decline after adjustment for confounding factors.

Results 7418 blood results from 326 patients were included. There was no relationship between serum sodium concentration and estimated glomerular filtration rate at baseline. After multivariable adjustment, a $1 \mathrm{mmol} / \mathrm{L}$ increase in baseline serum sodium was associated with a $1.5 \mathrm{~mL} / \mathrm{min} / 1.73 \mathrm{~m}^{2}$ decline in eGFR during the study period (95\% CI 0.9, 2.0). A reduction in eGFR was not associated with significant changes in serum sodium concentration over 6 years.

Conclusion Higher serum sodium concentration is associated with the progression of CKD, independently of other established risk factors. Conversely, significant alterations in serum sodium concentration do not occur with declining kidney function.
\end{abstract}

Keywords Serum sodium $\cdot$ Serum potassium $\cdot$ CKD progression $\cdot$ eGFR decline

\section{Introduction}

Higher dietary salt consumption in those with chronic kidney disease (CKD) is associated with increased blood pressure and proteinuria, independent risk factors for CKD progression [1]. The mechanisms underlying the adverse effects of salt are incompletely understood, but it has been proposed that small increases in serum sodium concentration are important $[2,3]$. In randomised-controlled trials, acute and large alterations in salt intake (ranging from less than

Nicholas I. Cole

nicholascole@nhs.net

1 South West Thames Renal Unit, Epsom and St Helier University Hospitals NHS Trust, Surrey, London SM5 1AA, UK

2 Wolfson Institute of Preventative Medicine, Queen Mary University of London, London, UK
$1 \mathrm{~g} /$ day to more than $10 \mathrm{~g} /$ day) are associated with parallel changes in serum sodium of up to $3 \mathrm{mmol} / \mathrm{L}$ [3]. Although changes in extracellular volume also occur, a significant positive correlation between serum sodium and blood pressure exists in both animals and humans when volume status is controlled using dialysis $[4,5]$. In addition, there is in vitro evidence that small increases in sodium concentration have a direct effect on the vascular endothelium: experiments have demonstrated stiffening of endothelial cells, damage to the glycocalyx layer and inhibition of nitric oxide release [6, 7]. Furthermore, increased sodium concentration has been shown to induce mRNA expression of many hypertrophyrelated factors, including transforming growth factor-beta (TGF- $\beta$ ), that are associated with the progression of CKD $[8,9]$.

Whilst significant abnormalities in serum sodium, especially hyponatraemia, have been consistently associated with mortality in CKD, the influence of small inter-individual 
differences has largely been ignored [10-13]. Higher serum sodium concentrations, within the normal range, have recently been reported be a risk factor for the development of incident CKD [14, 15]. However, whether there is a relationship between serum sodium and the progression of established CKD remains unknown. Therefore, we hypothesised that increased serum sodium is a risk factor for renal function decline and carried out a retrospective analysis to investigate this. We also considered the possibility that changes in serum sodium may occur secondary to CKD progression and altered sodium handling by the kidney.

\section{Methods}

\section{Study design and population}

This was a retrospective cohort study of data collected during a 6-year period. The South West Thames Renal Department database (Clinical Vision 5.3) was used to identify individuals under the follow-up of general nephrology services between January 2009 and December 2014. The primary outcome was the change in estimated glomerular filtration rate (eGFR) over the 6-year study period. In order to acutely assess this, the study was separated into three 2-year periods and only included individuals who had had at least three results during each of these periods. Data collected during the first 2-year period was used to determine baseline values. Individuals with a mean eGFR of $<60 \mathrm{~mL} /$ $\mathrm{min} / 1.73 \mathrm{~m}^{2}$ at baseline were included in the study. Exclusion criteria were as follows: provision of renal replacement therapy during the study period; a diagnosis of congestive cardiac failure, diabetes mellitus (type I or II), or decompensated liver disease prior to the study end date.

\section{Data collection}

Demographic details and laboratory values were extracted from the database and further information was identified manually from clinic letters including cause of CKD, comorbidity, office blood pressure and medication. Blood test results corresponding to the same date for serum sodium, potassium, creatinine and haematocrit were obtained and an eGFR was calculated for each creatinine value using the CKD-EPI equation [16]. Blood samples were processed at a number of laboratories in the local area, all of which are monitored by the United Kingdom National External Quality Assessment Service (NEQAS) to ensure comparable results. Serum creatinine was measured by enzymatic assay and serum sodium was determined using indirect potentiometry. In order to minimise the effect of acute illness or admission to hospital, blood tests were excluded from the analysis if any of the following applied: the sodium result was missing or significantly abnormal $(<125 \mathrm{mmol} / \mathrm{L}$ or $>155 \mathrm{mmol} / \mathrm{L})$; the sample was taken $\leq 7$ days apart from another blood test; there was an acute change in creatinine of $>50 \%$ from the previous baseline.

Baseline laboratory values were determined for each individual using the mean test result over the first 2 years of the study. Baseline proteinuria was estimated using urine protein:creatinine ratio (PCR) and urine albumin:creatinine ratio (ACR) results: significant proteinuria was defined as a mean PCR of $\geq 50 \mathrm{mg} / \mathrm{mmol}$ or a mean ACR of $\geq 30 \mathrm{mg} /$ mmol. Baseline blood pressure was calculated using the mean office measurement from visits during the baseline period. Where multiple measurements were recorded for a single visit, the lowest reading was used to minimise the 'white-coat' effect. Blood pressure control was defined as a mean systolic reading of $\leq 140 \mathrm{mmHg}$ and a mean diastolic reading of $\leq 90 \mathrm{mmHg}$. Finally, prescription data was obtained from nephrology clinic letters during the baseline period, using the most recent available medication list.

\section{Statistical analysis}

Data were analysed using R version 3.2.1 (2015-06-18) with a $P$ value of less than 0.05 being regarded as statistically significant. Changes in eGFR (and serum sodium) during the 6-year study period were determined for each individual using ordinary least squares regression coefficients, with time as the independent variable. Baseline analysis was carried out using univariate linear regression to obtain crude associations between serum sodium and eGFR, as well as other explanatory variables. Differences between two groups were analysed using the unpaired Student's t-test for normally-distributed variables. Multiple linear regression analysis was used to investigate the relationship between baseline serum sodium and eGFR decline, adjusting for potential confounding factors (age, sex, race, cause of CKD, blood pressure, proteinuria, baseline eGFR, serum potassium, haematocrit and medications). Blood pressure and proteinuria were included as categorical variables because of missing data. The model met the assumptions of normality, linearity and homoscedasticity, and influential outliers were not identified. Finally, linear regression was also used to investigate changes in serum sodium and potassium with eGFR decline.

\section{Results}

\section{Cohort selection and data completeness}

Figure 1 demonstrates an overview of the cohort selection process. This resulted in 7418 blood tests being included in the analysis for 326 individuals. Blood tests were collected over a mean period of 2,014 days (SD 132). For each 


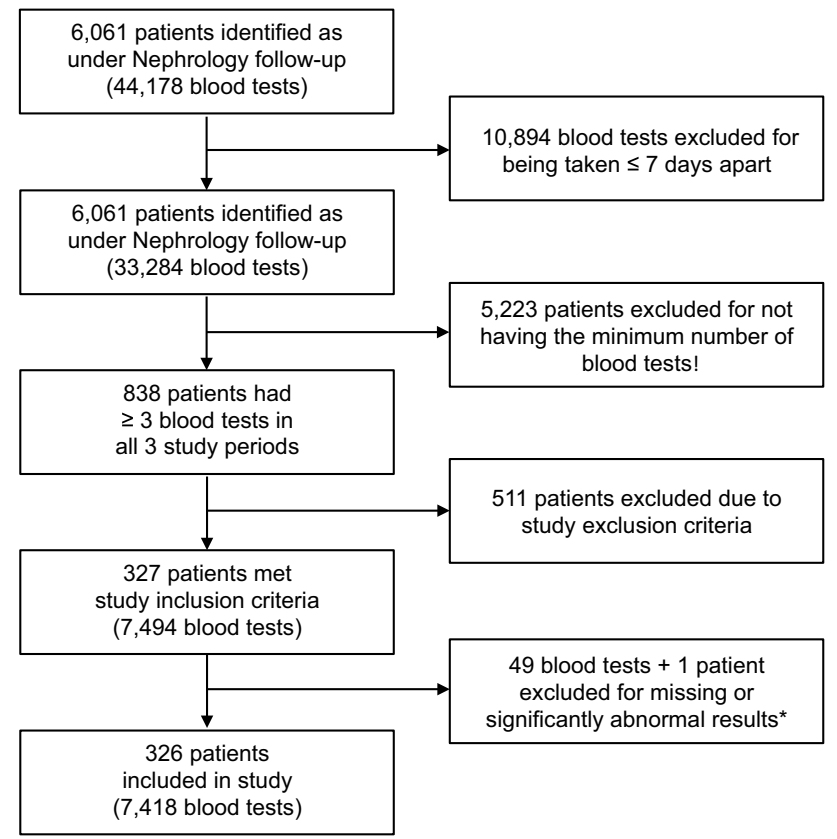

Fig. 1 Flowchart demonstrating an overview of the study cohort selection process. $*$ Significantly abnormal result $=$ sodium result of $<125$ or $>155 \mathrm{mmol} / \mathrm{L}$, or an acute change in creatinine of $>50 \%$ from the previous baseline

individual, there was a median of 7 (IQR 5-10) blood tests during the baseline period and 13 (IQR 10-19) during the follow-up period. Data was complete for age and sex, in addition to the blood test results. Non-white ethnicity was specified in 30 individuals (9\%), and cause of CKD was specified in $147(45 \%)$. Baseline blood pressure readings were obtained for 279 (86\%) of the cohort and baseline proteinuria estimations were available for $243(75 \%)$. Prescription data were for available for 278 individuals ( $85 \%$ ).

\section{Baseline associations with serum sodium}

The baseline characteristics of the cohort are shown in Table 1 . The mean eGFR was $34.2 \mathrm{~mL} / \mathrm{min} / 1.73 \mathrm{~m}^{2}$ (SD $11.0)$ and the mean serum sodium concentration was $139.7 \mathrm{mmol} / \mathrm{L}$ (SD 2.0). Univariate regression analysis showed a non-significant inverse relationship between eGFR and serum sodium at baseline. In comparison, there was a significant negative association between eGFR and serum potassium (a $1 \mathrm{mmol} / \mathrm{L}$ higher serum potassium was associated with a lower eGFR of $-7.1 \mathrm{~mL} / \mathrm{min} / 1.73 \mathrm{~m}^{2} ; 95 \% \mathrm{CI}$ $4.3,9.8)$. Figure 2 displays the differences in serum sodium and potassium by CKD stage.

At baseline, a $1 \mathrm{mmol} / \mathrm{L}$ higher serum sodium was associated with a higher haematocrit of $0.4 \%$ (95\% CI $0.2,0.6$ ). No relationship between serum sodium and blood pressure or proteinuria was demonstrated. The mean serum sodium
Table 1 Baseline characteristics of study cohort $(n=326)$

\begin{tabular}{|c|c|}
\hline Age in years (median, IQR) & $70(15)$ \\
\hline Female sex $(\mathrm{n}, \%)$ & $140(43)$ \\
\hline Non-white ethnicity (n, \%) & $30(9)$ \\
\hline \multicolumn{2}{|l|}{ Cause of CKD (n, \%) } \\
\hline Unspecified cause & $179(55)$ \\
\hline Glomerulonephritis/vasculitis & $61(19)$ \\
\hline Reflux/obstruction & $20(6)$ \\
\hline Renovascular/hypertension & $32(10)$ \\
\hline Other renal diagnoses & $34(10)$ \\
\hline \multicolumn{2}{|l|}{ Laboratory results } \\
\hline Sodium, mmol/L & $139.7 \pm 2.0$ \\
\hline Potassium, mmol/L & $4.7 \pm 0.4$ \\
\hline $\mathrm{eGFR}, \mathrm{mL} / \mathrm{min} / 1.73 \mathrm{~m}^{2}$ & $34.2 \pm 11.0$ \\
\hline Haematocrit, $\%$ & $38.6 \pm 4.0$ \\
\hline \multicolumn{2}{|l|}{ Proteinuria (n, \%) } \\
\hline None or low-level & $174(53)$ \\
\hline $\mathrm{PCR} \geq 50$ or $\mathrm{ACR} \geq 30 \mathrm{mg} / \mathrm{mmol}$ & $69(21)$ \\
\hline Unknown & $83(26)$ \\
\hline \multicolumn{2}{|l|}{ Blood pressure control (n, \%) } \\
\hline$\leq 140 / 90 \mathrm{mmHg}$ & $184(57)$ \\
\hline$>140 / 90 \mathrm{mmHg}$ & $95(29)$ \\
\hline Unknown & $47(14)$ \\
\hline \multicolumn{2}{|l|}{ Medications (n, \%) } \\
\hline Loop diuretic & $56(17)$ \\
\hline Thiazide diuretic & $54(17)$ \\
\hline Other diuretic & $6(2)$ \\
\hline RAS inhibitor & $193(59)$ \\
\hline Other antihypertensive agent & $167(51)$ \\
\hline Unknown & $48(15)$ \\
\hline
\end{tabular}

Data are shown as mean \pm standard deviation unless otherwise specified

$C K D$ chronic kidney disease, $e G F R$ estimated glomerular filtration rate (CKD-EPI equation), $P C R$ urine protein:creatinine ratio, $A C R$ urine albumin:creatinine ratio, $R A S$ renin:angiotensin system, $I Q R$ interquartile range

was lower in individuals prescribed diuretics compared to those not, but the difference was not significant (139.5 and $139.9 \mathrm{mmol} / \mathrm{L}$ respectively; $\mathrm{P}=0.17$ ). There was also no significant difference in serum sodium observed with the prescription of renin angiotensin system (RAS) inhibitors.

\section{Relationship between baseline serum sodium and CKD progression}

The mean decline in eGFR during the 6-year study period was $-4.2 \mathrm{~mL} / \mathrm{min} / 1.73 \mathrm{~m}^{2}$ (SD 10.7). On univariate analysis, a $1 \mathrm{mmol} / \mathrm{L}$ increase in serum sodium was associated with a $-1.4 \mathrm{~mL} / \mathrm{min} / 1.73 \mathrm{~m}^{2}$ decline in eGFR during the study (95\% CI $-2.0,-0.8$ ). Table 2 displays the results of the multiple regression model, with change in eGFR during the study 


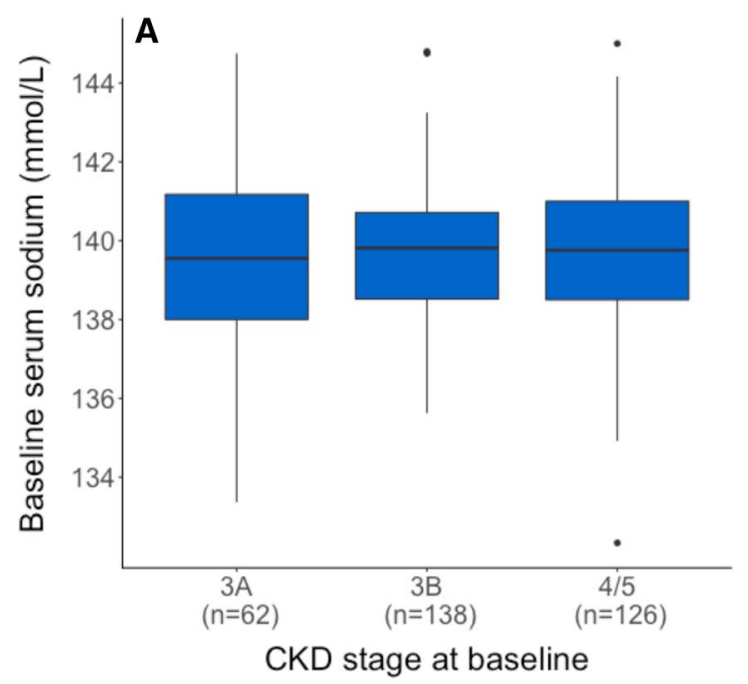

Fig. 2 Boxplots demonstrating serum electrolyte concentrations by CKD stage at baseline: a sodium; b potassium. CKD stage $3 \mathrm{~A}$ corresponds to an eGFR of between 45 and 59 , stage $3 \mathrm{~B}$ to an eGFR

period as the dependent variable. The variables included in this model accounted for $27 \%$ of the variation in eGFR change. Younger age, male gender, non-white ethnicity, proteinuria and a lower hematocrit at baseline were all significantly associated with a decrease in eGFR. In addition, there was a significant correlation with serum sodium such that a difference of $1 \mathrm{mmol} / \mathrm{L}$ at baseline was associated with a decline in eGFR of $-1.5 \mathrm{~mL} / \mathrm{min} / 1.73 \mathrm{~m}^{2}$ during the study $(95 \% \mathrm{CI}-2.0,-0.9)$. Serum potassium and the prescription of diuretics and/or RAS inhibitors were not associated with eGFR loss.

\section{Changes in serum sodium with eGFR decline}

The mean difference in serum sodium concentration between the baseline period and the final 2 years of the study was $0.3 \mathrm{mmol} / \mathrm{L}$ (SD 1.5). There was a trend for serum sodium concentration to decrease with greater reductions in eGFR during the study period, but this was not significant $(b=$ $-0.02 \mathrm{mmol} / \mathrm{L}$ for every $-1 \mathrm{~mL} / \mathrm{min} / 1.73 \mathrm{~m}^{2}$ reduction in eGFR; 95\% CI - 0.04, 0.00). Furthermore, no significant relationship was found in a subgroup analysis of individuals with an eGFR of $<30 \mathrm{~mL} / \mathrm{min} / 1.73 \mathrm{~m}^{2}$ at baseline $(\mathrm{n}=132)$. In comparison, for the whole cohort, a decrease in eGFR of $-1 \mathrm{~mL} / \mathrm{min} / 1.73 \mathrm{~m}^{2}$ was associated with a significant increase in serum potassium of $0.02 \mathrm{mmol} / \mathrm{L}(95 \% \mathrm{CI} 0.01,0.02)$.

\section{Discussion}

In this study, there was an association between higher serum sodium concentration and subsequent eGFR decline. After adjustment for confounding variables, a $5 \mathrm{mmol} / \mathrm{L}$

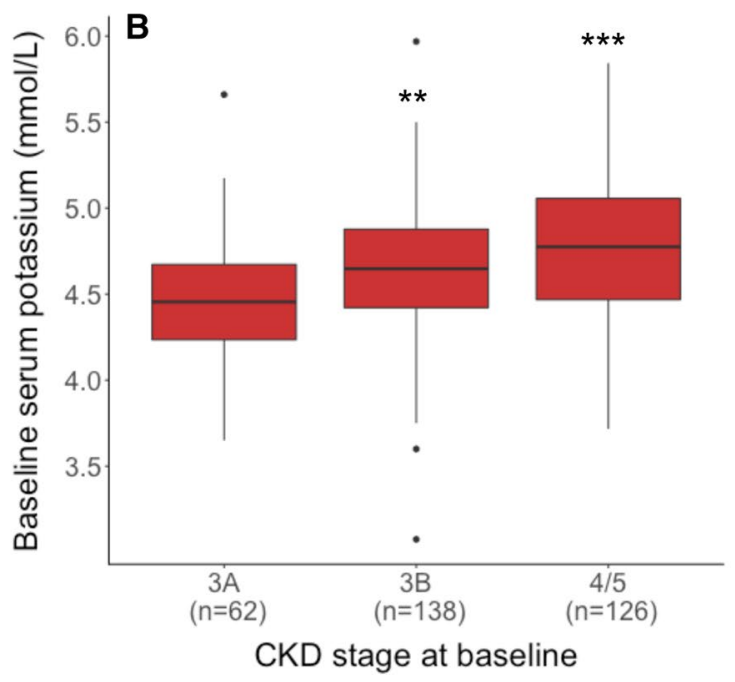

between 30 and 44 , and stage $4 / 5$ an eGFR of $<30 \mathrm{~mL} / \mathrm{min} / 1.73 \mathrm{~m}^{2}$. $* * \mathrm{P}<0.01 ; * * * \mathrm{P}<0.001$ (compared to CKD stage $3 \mathrm{~A}$ )

increase in baseline serum sodium was associated with a loss in eGFR of $-7.4 \mathrm{~mL} / \mathrm{min} / 1.73 \mathrm{~m}^{2}$ over 6 years in individuals with established CKD. This finding is interesting in that the association occurs within the normal range of serum sodium and it supports our primary hypothesis that increased serum sodium is a risk factor for CKD progression. It is also notable because adverse outcomes in CKD, in particular mortality, have more frequently been associated with hyponatraemia [10-13]. However, we excluded serum sodium results during acute illness and in those with significant co-morbidity including heart failure. Both may result in lower serum sodium and have a confounding influence on CKD progression, either as a consequence of decompensated disease or the initiation or up-titration of diuretic therapy.

Dietary salt may contribute to higher serum sodium concentrations but there was no association between serum sodium and blood pressure in this investigation. The use of office-based blood pressure readings was a limitation in this respect, but there could be alternative explanations for the relationship between increased serum sodium and eGFR decline. In particular, higher serum sodium could be an indicator of reduced extracellular volume, as evidenced by the significant positive relationship with haematocrit at baseline in our study. Although the effect of serum sodium on CKD progression was independent of this, haematocrit is a crude marker of hydration state and differences in extracellular volume cannot be excluded. However, at present there is limited evidence linking habitual water intake to serum sodium concentration or the progression of CKD [17, 18]: in the recently published CKD Water Intake Trial, increasing water intake did not result in significant alterations in either [18]. It is also interesting to speculate as to the potential 
Table 2 Multivariate linear regression analysis of factors associated with change in eGFR during the 6-year study period

\begin{tabular}{|c|c|c|c|}
\hline & $b$ & $95 \% \mathrm{CI}$ & $P$ value \\
\hline Age (years) & 0.14 & $0.05,0.23$ & $<0.01$ \\
\hline Female sex & 3.41 & $1.10,5.72$ & $<0.01$ \\
\hline Non-white ethnicity & -5.33 & $-9.13,-1.53$ & $<0.01$ \\
\hline \multicolumn{4}{|l|}{ Cause of CKD } \\
\hline Unspecified cause & {$[\mathrm{REF}]$} & {$[\mathrm{REF}]$} & {$[\mathrm{REF}]$} \\
\hline Glomerulonephritis/vasculitis & -0.57 & $-3.74,2.61$ & 0.73 \\
\hline Reflux/obstruction & -0.22 & $-4.91,4.46$ & 0.93 \\
\hline Renovascular/hypertension & 0.36 & $-3.34,4.07$ & 0.85 \\
\hline Other renal diagnoses & -2.75 & $-6.39,0.89$ & 0.14 \\
\hline \multicolumn{4}{|l|}{ Baseline laboratory results } \\
\hline Baseline sodium (mmol/L) & -1.47 & $-2.03,-0.91$ & $<0.001$ \\
\hline Baseline potassium (mmol/L) & -0.26 & $-3.13,2.61$ & 0.86 \\
\hline eGFR $\left(\mathrm{mL} / \mathrm{min} / 1.73 \mathrm{~m}^{2}\right)$ & 0.04 & $-0.08,0.16$ & 0.53 \\
\hline Haematocrit (\%) & 0.42 & $0.11,0.74$ & $<0.01$ \\
\hline \multicolumn{4}{|l|}{ Proteinuria } \\
\hline No proteinuria & {$[\mathrm{REF}]$} & {$[\mathrm{REF}]$} & {$[\mathrm{REF}]$} \\
\hline $\mathrm{PCR} \geq 50$ or $\mathrm{ACR} \geq 30 \mathrm{mg} / \mathrm{mmol}$ & -4.73 & $-7.73,-1.73$ & $<0.01$ \\
\hline Unknown & 2.22 & $-0.45,4.88$ & 0.10 \\
\hline \multicolumn{4}{|l|}{ Blood pressure control } \\
\hline$\leq 140 / 90 \mathrm{mmHg}$ & {$[\mathrm{REF}]$} & {$[\mathrm{REF}]$} & {$[\mathrm{REF}]$} \\
\hline$>140 / 90 \mathrm{mmHg}$ & 0.22 & $-2.29,2.72$ & 0.87 \\
\hline Unknown & -2.21 & $-6.64,2.23$ & 0.33 \\
\hline \multicolumn{4}{|l|}{ Medications } \\
\hline Loop diuretic & 1.29 & $-1.89,4.46$ & 0.43 \\
\hline Thiazide diuretic & 0.50 & $-2.55,3.55$ & 0.75 \\
\hline Other diuretic & 3.38 & $-4.69,11.44$ & 0.41 \\
\hline RAS inhibitor & -2.30 & $-4.86,0.27$ & 0.08 \\
\hline Other antihypertensive agent & -2.17 & $-4.63,0.29$ & 0.08 \\
\hline Unknown & -1.43 & $-6.28,3.42$ & 0.56 \\
\hline
\end{tabular}

$C K D$ chronic kidney disease, $e G F R$ estimated glomerular filtration rate (CKD-EPI equation), $P C R$ urine protein:creatinine ratio, $A C R$ urine albumin:creatinine ratio, $R A S$ renin:angiotensin system, $C I$ confidence interval

role of vasopressin release that occurs with higher sodium concentrations [19]. Following on from animal studies that have implicated a causal role for vasopressin in impaired renal function, there is a growing body of evidence demonstrating an association between copeptin levels (a surrogate marker of vasopressin) and eGFR decline in those with CKD $[20,21]$.

Finally, we found intra-individual serum sodium to be stable over the 6-year study period, consistent with recent reports of there being significant individuality in serum sodium concentration [22]. We considered the possibility that the advancement of CKD could affect the ability of the kidneys to regulate salt and water balance, particularly as a greater prevalence of hypernatraemia has been reported with progressive stages of CKD [10]. However, this study did not find that declining kidney function was associated with a significant change in serum sodium. There were also no significant alterations in serum sodium in a subgroup of individuals with CKD stages 4-5 at baseline, despite the fact that the capacity to produce concentrated urine declines with glomerular filtration rates less than $30 \mathrm{~mL} / \mathrm{min} / 1.73 \mathrm{~m}^{2}$ [23]. Whilst it is possible that the study was underpowered to detect such a change, this suggests that our primary findings are not explained by an effect of CKD progression on serum sodium.

\section{Limitations}

This study has a number of important limitations, including a relatively small cohort: the selective design was necessary in order to detect small changes in serum sodium in the presence of confounding variables. However, together with the retrospective design, this may have resulted in selection bias such that those with stable disease or those with rapidly progressive disease were excluded. Linear regression coefficients were used to estimate eGFR decline during the study but non-linear changes over time may limit the accuracy of this method. Furthermore, the data was collected routinely rather than for research purposes and this has implications for completeness and accuracy. In particular, there are limitations to using office blood pressure readings and prescription data may be unreliable due to dose alterations and compliance issues. Finally, the confounding effects of unmeasured factors influencing CKD progression cannot be excluded.

\section{Conclusion}

To our knowledge, this study is the first to demonstrate an association between higher serum sodium concentration and subsequent eGFR decline in people with established CKD. The observational nature of the study does not ascertain causality but, together with evidence that dietary salt intake increases serum sodium, this data is consistent with guidelines advocating the importance of salt restriction in this group. However, inter-individual differences in serum sodium concentration are not attributable to differences in salt intake alone. Further studies would be of value to further investigate the link between serum sodium, dietary salt, water intake and vasopressin activity, as well as their relationships with long-term health outcomes in those with CKD.

Funding None. 


\section{Compliance with ethical standards}

Conflict of interest FJH is a member of Consensus Action on Salt and Health (CASH) and World Action on Salt and Health (WASH). Both $\mathrm{CASH}$ and WASH are non-profit charitable organisations and FJH does not receive any financial support from CASH or WASH. GAM is chairman of Blood Pressure UK (BPUK), CASH and WASH. BPUK, $\mathrm{CASH}$ and WASH are non-profit charitable organizations. GAM does not receive any financial support from any of these organisations.

Ethical approval All procedures performed in studies involving human participants were in accordance with the ethicalstandards of the institutional and/or national research committee and with the 1964 Helsinki Declaration and its later amendments or comparable ethical standards.

Informed consent For this type of study, formal consent is not required.

Open Access This article is distributed under the terms of the Creative Commons Attribution 4.0 International License (http://creativeco mmons.org/licenses/by/4.0/), which permits unrestricted use, distribution, and reproduction in any medium, provided you give appropriate credit to the original author(s) and the source, provide a link to the Creative Commons license, and indicate if changes were made.

\section{References}

1. McMahon EJ, Campbell KL, Bauer JD, Mudge DW (2015) Altered dietary salt intake for people with chronic kidney disease. Cochrane Database Syst Rev 2:CD010070

2. de Wardener HE, He FJ, MacGregor GA (2004) Plasma sodium and hypertension. Kidney Int 66:2454-2466

3. He FJ, Markandu ND, Sagnella GA, de Wardener HE, MacGregor GA (2005) Plasma sodium: ignored and underestimated. Hypertension 45:98-102

4. Friedman SM, McIndoe RA, Tanaka M (1990) The relation of blood sodium concentration to blood pressure in the rat. J Hypertens 8:61-66

5. Suckling RJ, Swift PA, He FJ, Markandu ND, MacGregor GA (2013) Altering plasma sodium concentration rapidly changes blood pressure during haemodialysis. Nephrol Dial Transpl 28:2181-2186

6. Oberleithner H, Riethmüller C, Schillers H, MacGregor GA, de Wardener HE, Hausberg M (2007) Plasma sodium stiffens vascular endothelium and reduces nitric oxide release. Proc Natl Acad Sci 104:16281-16286

7. Oberleithner H, Peters W, Kusche-Vihrog K, Korte S, Schillers H, Kliche K, Oberleithner K (2011) Salt overload damages the glycocalyx sodium barrier of vascular endothelium. Pflugers Arch 462:519-528

8. Gu J-W, Sartin A, Elam J, Adair TH (2000) Dietary salt induces gene expression of hypertrophy-related factors in cultured human endothelial cells. Am J Hypertens 13(Suppl 2):F015

9. Loeffler I, Wolf G (2014) Transforming growth factor-beta and the progression of renal disease. Nephrol Dial Transpl 29(Suppl 1): $\mathrm{i} 37-\mathrm{i} 45$

10. Kovesdy CP, Lott EH, Lu JL, Malakauskas SM, Ma JZ, Molnar MZ, Kalantar-Zadeh K (2012) Hyponatraemia, hypernatraemia, and mortality in patients with chronic kidney disease with and without congestive cardiac failure. Circulation 125:677-684

11. Han SW, Tilea A, Gillespie BW, Finkelstein FO, Kiser MA, Eisele G, Kotanko P, Levin N, Saran R (2015) Serum sodium levels and patient outcomes in an ambulatory clinic-based chronic kidney disease cohort. Am J Nephrol 41:200-209

12. Chiu DY, Kalra PA, Sinha S, Green D (2016) Association of serum sodium levels with all-cause and cardiovascular mortality in chronic kidney disease: Results from a prospective observational study. Nephrology 21:476-482

13. Huang H, Jolly SE, Airy M, Arrigain S, Schold JD, Nally JV, Navaneethan SD (2017) Associations of dysnatremias with mortality in chronic kidney disease. Nephrol Dial Transpl 32:1204-1210

14. Nakajima K, Oda E, Kanda E (2016) The association of serum sodium and chloride levels with blood pressure and estimated glomerular filtration rate. Blood Press 25:51-57

15. Kuwabara M, Hisatome I, Roncal-Jimenez CA, Niwa K, AndresHernando A, Jensen T, Bjornstad P, Milagres T, Cicerchi C, Song Z, Garcia G, Sánchez-Lozada LG, Ohno M, Lanaspa MA, Johnson RJ (2017) Increased serum sodium and serum osmolarity are independent risk factors for developing chronic kidney disease; 5 year cohort study. PLoS One 12:e0169137

16. Stevens LA, Schmid CH, Greene T, Zhang YL, Beck GJ, Froissart M, Hamm LL, Lewis JB, Mauer M, Navis GJ, Steffes MW, Eggers PW, Coresh J, Levey AS (2010) Comparative performance of the CKD epidemiology collaboration (CKD-EPI) and the modification of diet in renal disease (MDRD) study equations for estimating GFR levels above $60 \mathrm{~mL} / \mathrm{min} / 1.73 \mathrm{~m}^{2}$. Am J Kidney Dis 56:486-495

17. Clark WF, Sontrop JM, Huang SH, Moist L, Bouby N, Bankir L (2016) Hydration and chronic kidney disease progression: a critical review of the evidence. Am J Nephrol 43:281-292

18. Clark WF, Sontrop JM, Huang SH, Gallo K, Moist L, House AA, Cuerden MS, Weir MA, Bagga A, Brimble S, Burke A, Muirhead N, Pandeya S, Garg AX (2018) Effect of coaching to increase water intake on kidney function decline in adults with chronic kidney disease: the CKD WIT randomized clinical trial. JAMA 319:1870-1879

19. Zerbe RL, Robertson GL (1983) Osmoregulation of thirst and vasopressin secretion in human subjects: effect of various solutes. Am J Physiol 244:E607-E614

20. Zittema D, van den Brand JAJG, Bakker SJL, Wetzels JF, Gansevoort RT (2017) Copeptin, a surrogate marker for arginine vasopressin, is associated with disease severity and progression in IgA nephropathy patients. Nephrol Dial Transpl 32(suppl 1):i146-i153

21. Boertien WE, Meijer E, Bost JE, Struck J, Flessner MF, Gansevoort RT, Torres VE, Consortium for Radiologic Imaging Studies of Polycystic Kidney Disease CRISP (2013) Relationship of copeptin, a surrogate marker for arginine vasopressin, with change in total kidney volume and GFR decline in autosomal dominant polycystic kidney disease: results from the CRISP cohort. Am J Kidney Dis 61:420-429

22. Zhang Z, Duckart J, Slatore CG, Fu Y, Petrik AF, Thorp ML, Cohen DM (2014) Individuality of the plasma sodium concentration. Am J Physiol Renal Physiol 306:F1534-F1543

23. Bricker NS, Dewey RR, Lubowitz H, Stokes J, Kirkensgaard T (1959) Observations on the concentration and diluting mechanisms of the diseased kidney. J Clin Invest 38:516-523 